Old Dominion University

ODU Digital Commons

Physics Faculty Publications

Physics

2019

\title{
Solutions for Fermi Questions, March 2019: Question 1: I'm Stoked!; Question 2: Geckos
}

Larry Weinstein

Old Dominion University, lweinste@odu.edu

Follow this and additional works at: https://digitalcommons.odu.edu/physics_fac_pubs

Part of the Engineering Physics Commons

\section{Repository Citation}

Weinstein, Larry, "Solutions for Fermi Questions, March 2019: Question 1: I'm Stoked!; Question 2: Geckos" (2019). Physics Faculty Publications. 380.

https://digitalcommons.odu.edu/physics_fac_pubs/380

\section{Original Publication Citation}

Weinstein, L. (2019). Solutions for Fermi questions, March 2019: Question 1: I'm stoked!; Question 2: Geckos. Physics Teacher, 57(3), A201. doi:10.1119/1.5092462 


\section{Fermi Questions}

\section{Solutions for Fermi Questions, March 2019}

\section{Duestion 1: I'm stoked!}

Old-fashioned steam engines were powered by coal transferred from the tender to the engine by human stokers using a shovel. What is the maximum power such an engine could attain?

Answer: We need to estimate the maximum sustained mass transfer rate, the energy density of coal, and the thermodynamic efficiency of the engine. One shovelful of coal will contain more than $1 \mathrm{~kg}$ and less than $10 \mathrm{~kg}$ (by volume, that would be more than $1 \mathrm{~L}$ and less than $10 \mathrm{~L}$ ), so we will estimate $3 \mathrm{~kg}$. It will take more than $1 \mathrm{~s}$ and less than $1 \mathrm{~min}$ to transfer a shovelful, so we will estimate $10 \mathrm{~s}$. That gives a mass transfer rate of $0.3 \mathrm{~kg} / \mathrm{s}$ or $1 \mathrm{ton} / \mathrm{hr}$. That is not crazy, since the mass transfer rate must be more than 0.1 ton $(100 \mathrm{~kg})$ and less than 10 tons per hour.

We have estimated the energy density of coal before (see Guesstimation: solving the world's problems on the back of a cocktail napkin), but we can do it again. Coal is made of carbon and oxidizes to $\mathrm{CO}_{2}$. Each chemical reaction liberates about $1.5 \mathrm{eV}$ (either 10\% of the binding energy of hydrogen, or the energy released per chemical reaction in a $1.5-\mathrm{V}$ battery, or between 10 and 100 times the kinetic energy per particle at room temperature). This gives

$$
e=(1.5 \mathrm{eV})\left(1.6 \times 10^{-19} \mathrm{~J} / \mathrm{eV}\right)\left(10^{2} \text { mole } \mathrm{C} / \mathrm{kg}\right)
$$

$\left(6 \times 10^{23}\right.$ atom $\left./ \mathrm{mole}\right)=2 \times 10^{7} \mathrm{~J} / \mathrm{kg}$,

or about $1 / 3$ that of gasoline. Published values on the internet vary from 10 to $30 \mathrm{MJ} / \mathrm{kg}$, so we're right in the middle.

The thermodynamic efficiency will be between $1 \%$ and $100 \%$, giving an estimate of $10 \%$. On the other hand, if we could attain the thermodynamic efficiency of modern coal-fired power plants, that would give us about $40 \%$ efficiency.

Thus, the maximum sustained power generated by an old-fashioned steam locomotive with one human stoker would have been

$$
\begin{aligned}
P & =\dot{M} \mathrm{e} \varepsilon \\
& =(0.3 \mathrm{~kg} / \mathrm{s})\left(2 \times 10^{7} \mathrm{~J} / \mathrm{kg}\right)(0.1) \\
& =6 \times 10^{5} \mathrm{~W},
\end{aligned}
$$

or about 1000 horsepower. Not bad for one person with 0.2 HP power output.

Copyright 2019, Lawrence Weinstein.

\section{Duestion 2: Geckos}

How many geckos would be needed to apply enough force to lift a typical glass window pane? How about a plate-glass window? Assume that we lift the pane by pulling up on all the geckos. (Thanks to Lucas Tracy of Old Dominion University for suggesting the question.)

Answer: We'll ignore the mechanics of how the geckos can lift the glass, and just consider how much force gecko feet can apply to the glass. We could analyze the structure of gecko feet and indulge in detailed biomechanical analyses, but, of course, we won't. Instead we will estimate the amount of force a gecko can apply in terms of its body weight. Since a gecko can walk on a ceiling, its feet can

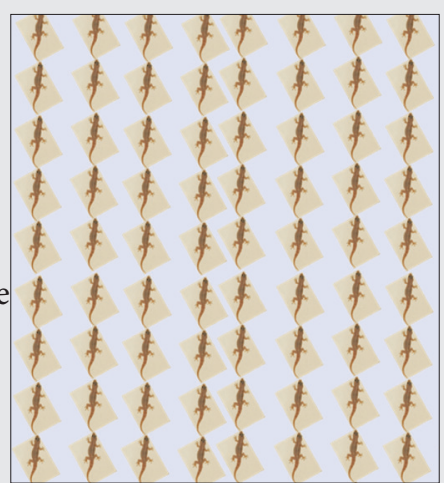

Gecko image from https://upload. wikimedia.org/wikipedia/commons/thumb/d/da/Hemidactylus frenatus_9701.jpg/1200px-Hemidactylus_frenatus_9701.jpg. clearly exert more force than the weight of its body. Since geckos do not run across ceilings, we'll assume that their feet cannot exert 10 times their body weight. Therefore, we'll take the geometric mean of 1 and 10 and estimate that gecko feet can exert a force on a flat surface equal to three times their body weight.

Now we need to estimate the relative masses of geckos and glass panes. Geckos are small lizards with a length of about $10 \mathrm{~cm}$ (definitely more than $1 \mathrm{~cm}$ and less than $1 \mathrm{~m}$ ) and widths and thicknesses of about $1 \mathrm{~cm}$, giving a volume of $10 \mathrm{~cm}^{3}$ and therefore a mass of $10 \mathrm{~g}$. (Reality check: geckos range from $1.6 \mathrm{~cm}$ to $64 \mathrm{~cm}$, so $10 \mathrm{~cm}$ is nicely in the middle of that.)

A typical window pane will be $1 \mathrm{~m}$ by $1 \mathrm{~m}$ by $1 \mathrm{~mm}$ with a volume of $10^{-3} \mathrm{~m}^{3}$. Its density will be more than 1 (water) and less than 10 (iron), so we'll estimate 3, giving a mass of $3 \mathrm{~kg}$. Since we can lift 30 -g per gecko, we will need 100 geckos to lift the glass pane.

A plate glass window is about $1 \mathrm{~cm}$ thick, or about 10 times thicker than a simple window pane. That means we'll need 10 times more geckos. That is a lot of geckos! It will be very hard to fit that many on the 1-m square slab. This seems like a very impractical way of lifting glass panes. Copyright 2019, Lawrence Weinstein. 